\title{
CONHECIMENTO DOS ENFERMEIROS SOBRE O NOVO PROTOCOLO DE RESSUSCITAÇÃO CARDIOPULMONAR
}

\section{NURSES' KNOWLEDGE ON THE NEW CARDIOPULMONARY RESUSCITATION PROTOCOL}

\section{CONOCIMIENTO DE ENFERMEROS EN EL NUEVO PROTOCOLO DE REANIMACIÓN CARDIOPULMONAR}

Flávia Batista Barbosa de Sá Diaz ${ }^{1}$, Maria Eduarda Ferreira Novais ${ }^{2}$, Katiusse Rezende Alves ${ }^{3}$, Luciano Paiva Cortes ${ }^{4}$, Tiago Ricardo Moreira $^{5}$

\section{RESUMO}

Objetivo: Avaliar o conhecimento de enfermeiros sobre o atendimento à parada cardiorrespiratória (PCR), suporte básico e avançado de vida cardiovascular, tendo como base as novas diretrizes de Ressuscitação Cardiopulmonar (RCP) da American Heart Association (AHA) do ano de 2015. Métodos: Trata-se de um estudo descritivo de abordagem quantitativa, realizado no hospital escola de um município do interior de Minas Gerais, através da aplicação de um questionário fechado, elaborado pelas pesquisadoras. Os dados coletados foram processados pelo Statistical Package for the Social Sciences (SPSS) versão 20. Resultados: Participaram do estudo 19 enfermeiros. O número de acertos dos participantes no questionário oscilou entre 0 a $100 \%$, com média de 4,2 e desvio padrão de 3,2. Foi classificado, como conhecimento satisfatório, o número de acertos superior e/ou igual a $70 \%$ e o conhecimento insatisfatório, o número inferior a $70 \%$. Apenas $26,4 \%$ dos enfermeiros obtiveram conhecimento satisfatório. Conclusão: Constatou-se que enfermeiros não possuem conhecimento satisfatório sobre as mudanças propostas pelas novas diretrizes de RCP da AHA de 2015.

Descritores: Enfermagem; Parada cardíaca; Ressuscitação cardiopulmonar; Estudantes de enfermagem.

\section{ABSTRACT:}

Objective: To evaluate nurses' knowledge about cardiorespiratory arrest care (CRP), basic and advanced cardiovascular life support, based on the new American Heart Association (AHA) Cardiopulmonary Resuscitation (CPR) guidelines of 2015. Methods: This is a descriptive study of a quantitative approach, carried out at the school hospital of a municipality in the interior of Minas Gerais, through the application of a closed questionnaire prepared by the researchers. Statistical Package for the Social Sciences (SPSS) version 20 processed the collected data. Results: Nineteen nurses participated in the study. The number of correct answers of the participants in the questionnaire ranged from zero to $100 \%$, with an average of 4.2 and a standard deviation of 3.2 . This study classified that when the number of hits is higher and/or equal to $70 \%$, there is satisfactory knowledge and the number less than $70 \%$, unsatisfactory knowledge. Only $26.4 \%$ of the nurses had satisfactory knowledge. Conclusion: This study found that nurses do not have satisfactory knowledge about the changes proposed by the new AHA CPR guidelines of 2015 .

Descriptors: Nursing; Cardiac arrest; Cardiopulmonary resuscitation; Nursing students.

\section{RESUMEN:}

Objetivo: Evaluar el conocimiento de los enfermeros acerca de la atención a la parada cardiorrespiratoria (PCR), soporte básico y vital cardiovascular avanzado, basado en las nuevas directrices para la resucitación cardiopulmonar (CPR) de la American Heart Association (AHA) en el año 2015. Métodos: Este es un estudio descriptivo de abordaje cuantitativo, realizado en el hospital escuela en una ciudad en Minas Gerais por la aplicación de un cuestionario cerrado preparado por las investigadoras. Los datos recogidos fueron procesados por el Paquete Estadístico para Ciencias Sociales (SPSS) versión 20. Resultados: En el estudio participaron 19 enfermeros. El número de respuestas correctas de los participantes en el cuestionario varió de 0 a $100 \%$, con un promedio de 4,2 y la desviación estándar de 3,2. Se clasificó como conocimiento satisfactorio, el número de aciertos por encima y/o iguales de $70 \%$ y el conocimiento insatisfactorio, el número menos de $70 \%$. Sólo el $26,4 \%$ de los enfermeros han obtenido un conocimiento satisfactorio. Conclusión: Se encontró que los enfermeros no tienen un conocimiento adecuado sobre los cambios propuestos por las nuevas directrices de RCP 2015 de la AHA.

Descriptores: Enfermería; Paro cardiaco; Resucitación cardiopulmonar; Estudiantes de enfermería.

${ }^{1}$ Graduada e Licenciada em Enfermagem. Mestre em Saúde Coletiva pela Faculdade de Medicina da Universidade Federal de Juiz de Fora. Docente na Universidade Federal de Viçosa. ${ }^{2}$ Graduanda em Enfermagem pela Universidade Federal de Viçosa. ${ }^{3}$ Graduada em Enfermagem. Mestre em Enfermagem pela Universidade Federal de Juiz de Fora. Docente na Universidade Federal de Viçosa. ${ }^{4}$ Graduado em Enfermagem pela Universidade Salgado de Oliveira. Professor Substituto na Universidade Federal de Viçosa. ${ }^{5}$ Graduado em Enfermagem. Doutor em Saúde Pública pela Universidade Federal de Minas Gerais. Docente na Universidade Federal de Viçosa.

Como citar este artigo:

Diaz FBBS, Novais MEF, Alves KR, et al. Conhecimento dos enfermeiros sobre o novo protocolo de ressuscitação cardiopulmonar. 2017;7:e1822. [Access ]; Available in: . https://doi.org/10.19175/recom.v7i0.1822 


\section{INTRODUÇÃO}

A parada cardiorrespiratória (PCR) é a cessação súbita, inesperada, da circulação sistêmica, atividade ventricular útil e ventilatória de um indivíduo. Ela é considerada uma das maiores emergências na qual um profissional de saúde pode se deparar ao longo de sua atuação, exigindo dos mesmos, uma conduta rápida e eficaz para reversão do quadro e melhor prognostico da vítima ${ }^{(1)}$.

No século passado, a PCR era sinônimo de morte devido ao conhecimento deficiente neste tipo de atendimento e, não mais que $2 \%$, sobreviviam. Atualmente, este índice de sobrevida chega a ultrapassar $70 \%$ se o socorro for precoce e eficiente ${ }^{(2)}$. Estudos apontam que a sobrevida, após uma PCR, varia de 2 a $49 \%$ e que esses valores estão diretamente relacionados ao ritmo cardíaco inicial e ao início precoce da ressuscitação cardiopulmonar (RCP). Além disso, a sobrevivência pode dobrar ou triplicar se as manobras de ressuscitação forem realizadas com qualidade $^{(1,3)}$.

É sabido que as ações realizadas durante os minutos iniciais de atendimento a uma emergência são cruciais para a sobrevivência da vítima $^{(1)}$. O suporte básico de vida (SBV) consiste no atendimento inicial ao paciente vítima de PCR e consiste na identificação da PCR, acionamento da equipe de atendimento, início das compressões torácicas (C), abertura de vias aéreas (A), ventilação (B) e desfibrilação precoce $^{(4-5)}$.

Já o suporte avançado de vida cardiovascular (SAVC) corresponde ao atendimento secundário, conhecido como $A B C D$ secundário, em que são realizados os procedimentos como a obtenção de uma via aérea definitiva para uma ventilação adequada, acesso para infusão de medicações vasoativas e/ou antiarrítmicas e o diagnóstico diferencial da PCR - 5H's (hipovolemia, hipóxia, H+/acidose, hipo/hiperpotassemia, hipotermia) e 5T's (trombose coronária, trombose pulmonar, tensão no tórax, tamponamento cardíaco e toxinas/intoxicação) $)^{(6)}$.

O SBV define a sequência primária de ações para salvar vidas e, por mais adequado e eficiente que seja um suporte avançado, se as ações de suporte básico não forem realizadas adequadamente, será extremamente baixa a possibilidade de sobrevivência de uma vítima de $\mathrm{PCR}^{(1)}$.
Desde o ano de 1974, a American Heart Association (AHA) tem publicado Guidelines acerca da RCP, que a partir do ano 2000 se atualizam a cada 5 anos. A mais recente atualização ocorreu em 2015, em parceria com a International Liaison Committee on Resuscitation (ILCOR), em que apontaram as mudanças necessárias para melhoria do atendimento à $P C R^{(5)}$.

Observa-se que, na maioria das vezes, os profissionais de enfermagem são os primeiros a identificar os pacientes que se encontram em PCR, uma vez que assistem diretamente o paciente. Portanto, cabe a eles a necessidade do conhecimento atualizado, com as diretrizes internacionais e habilidades bem desenvolvidas para que a RCP seja prestada com qualidade ${ }^{(3,5,7)}$. Além disso, é necessário que o enfermeiro, enquanto líder da equipe de enfermagem, saiba tomar decisões rápidas e estabelecer as prioridades deste atendimento, de forma a sistematizá-lo e organizá-lo, para melhor desempenho de sua equipe e para maior segurança do paciente ${ }^{(8)}$.

Estudos têm demonstrado que os profissionais de enfermagem apresentam lacunas no conhecimento acerca do atendimento à $\mathrm{PCR}^{(3,7,9)}$. A AHA destaca que uma equipe dedicada, com experiência, especialização, formação adequada e treinamento, desempenha melhor suas habilidades e minimizam os erros neste tipo de atendimento ${ }^{(10)}$.

Diante disso, este estudo teve como objetivo avaliar o conhecimento dos enfermeiros sobre o atendimento à PCR em adultos, suporte básico e avançado de vida cardiovascular, tendo como base as novas diretrizes de RCP da AHA do ano de 2015.

\section{MÉTODOS}

Este estudo é parte integrante do projeto de extensão e pesquisa intitulado 'Primeiros socorros: educando a comunidade e os profissionais de saúde do município de ViçosaMG e região'. Tratou-se de um estudo transversal, descritivo, de caráter quantitativo, realizado em um hospital escola de médio porte do interior de Minas Gerais nos meses de abril a maio de 2016.

A coleta de dados se deu através da aplicação de um questionário elaborado pelas pesquisadoras, contendo duas partes. A primeira, composta por variáveis sociodemográficas e a 
segunda por 10 questões fechadas de múltipla escolha, com apenas uma opção de alternativa correta.

Foi avaliado, nas questões, o conhecimento referente: ao reconhecimento do paciente em $P C R$, à abordagem profissional a ser feita imediatamente após o reconhecimento da mesma, ao algoritmo CAB (Compressões, Abertura de vias áreas e Breathing/ventilações), à profundidade e à frequência das compressões torácicas a serem realizadas na RCP, aos ritmos cardíacos chocáveis em uma PCR, aos cuidados com a desfibrilação durante a RCP, à quantidade e qualidade de ventilações por minuto que deverão ser realizadas neste tipo de atendimento após inserção da via aérea definitiva, aos medicamentos utilizados no SAVC e ao reconhecimento do diagnóstico diferencial durante e após a PCR.

O critério de inclusão deste estudo foi ser enfermeiro do referido hospital. Os critérios de exclusão foram: estar afastado do exercício do trabalho por motivo de férias, atestado médico ou qualquer outro motivo durante a aplicação do questionário.

O número total de enfermeiros que atuam nesse hospital corresponde a 23. Participaram do estudo, os enfermeiros dos seguintes setores: coordenação hospitalar, serviços de controle de infecção hospitalar, urgência e emergência, clínica médica, clínica cirúrgica, centro cirúrgico, centro de terapia intensiva, agência transfusional e clínica psiquiátrica, totalizando 19 enfermeiros (82,6\% do total). Dos quatro profissionais que não participaram da pesquisa, dois estavam de férias, um de atestado médico e um não teve disponibilidade de horário para aplicação do questionário.

O estudo foi realizado respeitando-se os aspectos éticos estabelecidos na Resolução no 466/2012 do Ministério da Saúde/Conselho
Nacional de Saúde, após aprovação do projeto pelo Comitê de Ética em Pesquisa com Seres Humanos da Universidade Federal de Viçosa (UFV) em 2014, protocolo número 870.833 e após anuência dos participantes, com a assinatura do Termo de Consentimento Livre e Esclarecido (TCLE).

Os dados foram analisados através da estatística descritiva, utilizando-se o Statistical Package for the Social Sciences (SPSS) versão 20, sendo determinados a média e o desvio padrão da população estudada. Foi classificado como conhecimento satisfatório, o número de acertos dos participantes superior e/ou igual a $70 \%$ no questionário aplicado e, como conhecimento insatisfatório, o número inferior a 70\%.

\section{RESULTADOS E DISCUSSÃO}

Participaram do estudo, 19 enfermeiros, representando $82,6 \%$ da população total da pesquisa, sendo a maioria do sexo feminino $(68,4 \%)$, com a faixa etária de 25 a 30 anos $(42,1 \%)$, com tempo de formação entre um a cinco anos $(52,6 \%)$, com atuação profissional no local da pesquisa de um a cinco anos $(52,6 \%)$, sem outro vínculo empregatício $(57,9 \%)$ e com carga de trabalho semanal de 40 horas $(47,4 \%)$. Observou-se que grande parte dos enfermeiros já realizou alguma capacitação em $\operatorname{RCP}(63,2 \%)$, sendo que do total de enfermeiros, $47,4 \%$ realizaram há um ano e $15,8 \%$ realizaram há mais de um ano. $\mathrm{O}$ conhecimento sobre suporte básico e avançado de vida foi classificado como bom $(63,2 \%)$ pelos participantes, segundo a escala de Likert (ótimo, muito bom, bom, regular, ruim).

Quanto ao número de acertos dos participantes nas questões de múltipla escolha, foram observados os seguintes percentuais de acertos por questão (Figura 1):

Figura 1- Porcentagem de acertos dos participantes em cada questão.

\begin{tabular}{|c|c|c|c|}
\hline Questão & Tema & Acertos & Porcentagem \\
\hline 01 & Reconhecimento de Parada & 9 & $47,4 \%$ \\
\hline 02 & Número e profundidade das compressões & 10 & $52,6 \%$ \\
\hline 03 & Prioridade de atendimento em paciente em PCR & 7 & $36,8 \%$ \\
\hline 04 & Ritmos Chocáveis & 10 & 52,6 \\
\hline
\end{tabular}




\begin{tabular}{|c|c|c|c|}
\hline 05 & Ventilação durante PCR & 8 & $42,1 \%$ \\
\hline 06 & Diagnósticos Diferenciais & 5 & $26,3 \%$ \\
\hline 07 & O que fazer após desfibrilação & 5 & $26,3 \%$ \\
\hline 08 & Algoritmo CAB do SBV & 12 & $63,2 \%$ \\
\hline 09 & Relação de compressões por ventilações no SBV e \\
no SAVC & 8 & $42,1 \%$ \\
\hline 10 & $\begin{array}{c}\text { Medicação } \\
\text { nat }\end{array}$ & 6 & $31,6 \%$ \\
\hline
\end{tabular}

Fonte: Elaborado pelos autores com base na coleta de dados da pesquisa, 2016.

A figura a seguir (Figura 2) representa o número de participantes e sua respectiva quantidade de acertos no questionário:

Figura 2- Número de participantes e quantidade de acertos

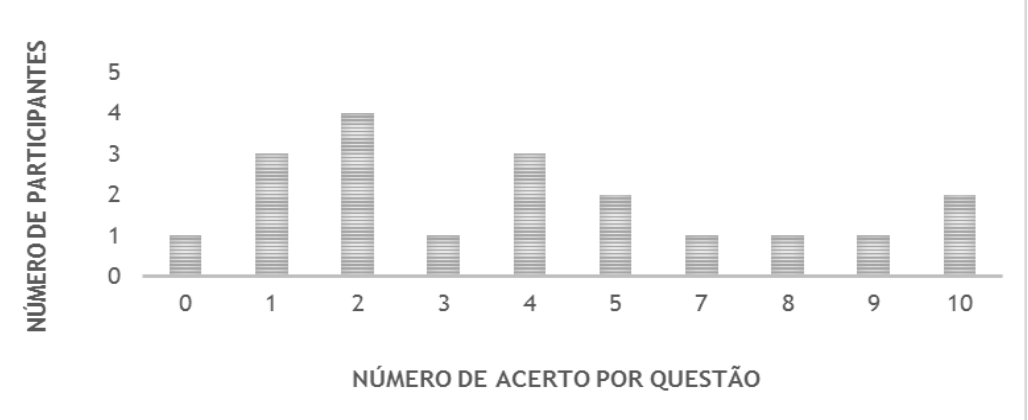

Fonte: Elaborado pelos autores com base na coleta de dados da pesquisa, 2016.

O número de acertos dos participantes, no questionário, oscilou entre 0 a 100\%, sendo que, apenas $26,4 \%$ obtiveram conhecimento satisfatório (Figura 3).

Figura 3- Conhecimento satisfatório e insatisfatório dos participantes acerca do atendimento à PCR

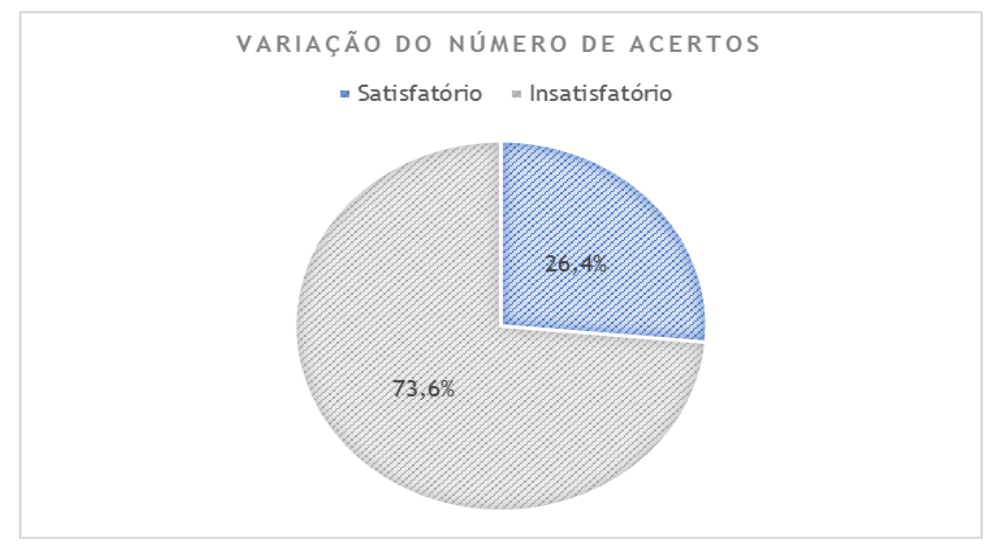

Fonte: Elaborado pelos autores com base na coleta de dados da pesquisa, 2016. 
A população pesquisada apresentou distribuição normal no gráfico da curtose e assimetria e no teste Kolmogorov-Smirnov $(p>0,05)$, com média de acertos no questionário de 4,2 e desvio padrão de 3,2 .

Ao comparar a média de acertos dos participantes que realizaram capacitação prévia em RCP com aqueles que não realizaram, observou-se, no teste $T$, que o grupo que realizou alguma capacitação obteve maior média de acertos, sendo este resultado estatisticamente significativo, com $p<0,005$.

É de suma importância que os profissionais de saúde tenham habilidade, não só de reconhecer rapidamente os sinais que a vítima de PCR demonstra, como também de realizar as manobras de RCP o mais rápido possível. Tais ações aumentam, consideravelmente, a probabilidade de sucesso e de reversão do quadro de PCR, reduzindo o índice de mortalidade e morbidade ${ }^{(2,3,8,11)}$.

Para o reconhecimento de uma PCR, devese, primeiramente, avaliar a responsividade da vítima e, em seguida, observar a presença de movimentos respiratórios e de pulso central, simultaneamente $e^{(5)}$.

Após avaliar esses parâmetros, é possível realizar a intervenção de forma rápida e proporcionar maior chance de sobrevida para a vítima. Quando a intervenção é realizada de forma ágil e correta, a taxa de sobrevida é de $75 \%$, se a intervenção ocorre nos primeiros 4 minutos; de $15 \%$, se ocorre entre 4 e 12 minutos e, apenas de $5 \%$, se ocorre após 15 minutos $^{(1,3)}$.

Neste estudo, verificou-se que apenas $45 \%$ dos enfermeiros sabiam identificar a PCR. Outros estudos também evidenciaram uma limitação no conhecimento e na agilidade dos mesmos, frente ao atendimento à $\mathrm{PCR}^{(3,12)}$. Pesquisa realizada com 73 enfermeiros de 16 unidades, de sete municípios da Região Metropolitana de Campinas, apontou que mais de $60 \%$ dos participantes não foram capazes de detectar corretamente uma $\mathrm{PCR}^{(7)}$.

Em contrapartida, houve pesquisas que evidenciaram um alto percentual de acerto, no que se refere a esta abordagem, respectivamente, de $98 \%$ e $82 \%^{(7,13)}$. Sendo assim, observou-se que não há consenso entre os estudos quanto aos resultados encontrados.

Após a identificação da PCR, inicia-se a RCP com a realização das compressões torácicas, que são essenciais para gerar fluxo sanguíneo suficiente para levar oxigênio aos órgãos e tecidos. Quando a compressão torácica é realizada de maneira adequada, com profundidade e frequência corretas, a chance de sobrevida da vítima aumenta substancialmente ${ }^{(5)}$. No presente estudo, observou-se que $50 \%$ dos profissionais de saúde têm conhecimento sobre como realizar a manobra de RCP de forma correta.

Um estudo realizado com enfermeiros de um serviço de urgência e emergência da Região Metropolitana de Campinas demonstrou que 60\% dos profissionais de enfermagem não realizavam esta manobra da maneira correta ${ }^{(8)}$. Já em outro estudo, a maioria, $68,7 \%$ dos enfermeiros, demonstrou conhecimento acerca da técnica de compressão torácica ${ }^{(3)}$.

Uma pesquisa, realizada com objetivo de analisar o conhecimento da equipe de enfermagem diante do reconhecimento de uma PCR e sobre a RCP (diretrizes da AHA do ano de 2010), revelou que apenas $20,6 \%$ dos participantes realizavam a compressão torácica de forma adequada ${ }^{(9)}$. Cabe destacar que erros nesta etapa do atendimento podem comprometer significativamente a qualidade da $R C P$, pois a ênfase do atendimento ao paciente adulto em PCR é a realização de compressões torácicas efetivas, rápidas $\left(\begin{array}{lll}100 & \text { a } & 120\end{array}\right.$ compressões por minuto) e fortes (com profundidade torácica de 5 a $6 \mathrm{~cm})^{(5,9)}$.

Além do reconhecimento de uma PCR e realização correta da manobra de $R C P$, é necessário que a equipe reconheça os ritmos cardíacos para que, se em ritmo chocável, a desfibrilação possa ocorrer precocemente ${ }^{(5)}$.

No Brasil, a responsabilidade pela realização deste procedimento é apenas do profissional médico. Porém, é dever do enfermeiro, monitorizar precocemente o paciente e distinguir os ritmos chocáveis - que são fibrilação ventricular (FV) e taquicardia ventricular(TV) - dos não chocáveis, como assistolia e atividade elétrica sem pulso (AESP), 
para que a desfibrilação possa ocorrer de forma mais rápida. Esta conduta aumenta as chances de sobrevida do paciente ${ }^{(2,7)}$.

Este estudo demonstrou que $50 \%$ dos enfermeiros souberam identificar os ritmos chocáveis da PCR, dado que corrobora com outra literatura, cujo índice de acertos foi de $60 \%{ }^{8}$. Já em outra pesquisa, apenas $25 \%$ dos enfermeiros entrevistados identificaram corretamente estes ritmos $^{(3)}$.

Dando continuidade a este estudo do atendimento, procede-se ao SAVC. A abordagem secundária da PCR enfatiza a necessidade de providenciar uma via aérea avançada. Uma vez que o paciente já se encontra com a via aérea avançada, as compressões e ventilações não devem ser realizadas de forma sincronizada (30 compressões por 2 ventilações), mas, simultaneamente, ou seja, 100 a 120 compressões por minuto e 1 ventilação a cada 6 segundos, resultando em 10 ventilações por minuto $^{(6)}$.

Os participantes do atual estudo apresentaram conhecimento escasso sobre o número de ventilações e compressões realizadas após intubação do paciente, como em outros estudos realizados ${ }^{(7,14)}$. Um destes estudos mencionados foi realizado com profissionais de uma Unidade de Terapia Intensiva (UTI) e, supreendentemente, mesmo com um número predominante de pacientes já intubados no setor, apenas $15 \%$ dos participantes souberam responder de forma correta a relação entre ventilação e compressão após intubação ${ }^{(7)}$.

Destaca-se também, no SAVC, a definição do diagnóstico diferencial da PCR e do tratamento de sua causa-base. As principais causas de PCR são conhecidas como os $5 \mathrm{Hh}$ e $5 \mathrm{Tt}^{(6)}$. É de extrema importância que estas causas sejam identificadas de maneira ágil para serem tratadas de forma precisa, com intuito de reverter a $\mathrm{PCR}^{(14)}$. Na pesquisa realizada, os conhecimentos sobre as possíveis causas da PCR foram baixos ( $25 \%$ de acertos), o que se diferenciou de outro estudo, que obteve resultado bem superior $(70,8 \% \text { de acertos })^{(15)}$.

A cada cinco anos, a AHA traz novas recomendações sobre RCP e uma das atualizações do protocolo de 2015 foi a retirada de vasopressina do SAVC, visto que seu uso combinado com epinefrina não oferece nenhuma vantagem em comparação ao uso da dose padrão desta última em PCR. Além disso, a vasopressina não oferece nenhuma vantagem sobre $\mathrm{O}$ uso isolado de epinefrina. Assim, para simplificar o atendimento, a vasopressina foi retirada do algoritmo de atendimento do $\mathrm{SAVC}^{(6)}$. O conhecimento dos participantes sobre essa mudança foi baixo, apenas $40 \%$ conheciam esta atualização.

As diretrizes da AHA foram elaboradas com a finalidade de adequar $\mathrm{O}$ atendimento dos profissionais de saúde a uma $P C R$, onde os mesmos possam realizar, adequadamente, a RCP, baseando-se na ciência e, consequentemente, gerar maior sobrevida à vítima assistida. Entretanto, o conhecimento e atualização da equipe de enfermagem sobre tais diretrizes são de suma importância para o sucesso do atendimento, visto que, na maioria das vezes, é a equipe de enfermagem que se depara com situações de PCR, tendo que dispor de conhecimento teórico e prático a fim de realizar um atendimento adequado e de alta qualidade $\mathrm{e}^{(3,7,16)}$.

É fundamental que a educação permanente seja fornecida às equipes que atendem às urgências, pois proporciona uma articulação da teoria com a prática, indo ao encontro da necessidade de atualização, devido às constantes mudanças em protocolos assistenciais. Esta atualização visa à promoção de uma assistência segura, organizada e uniformizada, contribuindo para redução de iatrogenias ${ }^{(9,14,17)}$.

Um estudo realizado - com objetivo de determinar se os pacientes atendidos por enfermeiros treinados em ACLS teria taxas de sobrevivência diferente daqueles atendidos por enfermeiros não treinados - demonstrou que o treinamento deste profissional está fortemente associado ao aumento da sobrevida do paciente ${ }^{(18)}$. Outro estudo semelhante ao mencionado anteriormente, também demonstrou que a presença de, pelo menos um membro da equipe treinado em ACLS, aumenta a sobrevivência do paciente a curto e longo prazo após sua reanimação ${ }^{(19)}$.

Destarte, é de grande importância realizar treinamentos periódicos em RCP com a finalidade de capacitar as equipes para $O$ atendimento rápido, seguro e eficaz, dentro do que é preconizado pelas diretrizes internacionais. Destaca-se que o enfermeiro, enquanto líder da equipe de enfermagem, é responsável pela capacitação da mesma ${ }^{(3)}$.

Assim sendo, foi visível que os enfermeiros do presente estudo possuem um déficit no conhecimento teórico, comprovado pelo baixo 
índice de acertos, principalmente sobre reconhecimento em PCR, como realizar as manobras de RCP e sobre os diagnósticos diferenciais. Estes dados não são diferentes de outros dois estudos: um, realizado no hospital urgência e emergência de Rio Branco (Acre) e outro, num hospital público de Minas Gerais, onde também demonstraram deficiência no conhecimento destes profissionais sobre as diretrizes da $\operatorname{RCP}^{(13,15)}$.

\section{CONCLUSÃO}

As frequentes atualizações no conhecimento da área de saúde exigem que os profissionais estejam sempre se capacitando e se qualificando para prestar um atendimento de excelência ao paciente. Este estudo mostrou que o conhecimento dos enfermeiros sobre o atendimento à PCR é insatisfatório, podendo assim, influenciar na qualidade da assistência prestada e na sobrevida do paciente nesta situação.

Diante do exposto, percebe-se a necessidade de realizar capacitações periódicas para este público, a fim de atualizar seus saberes e práticas relacionados ao SBV e SAVC, segundo recomendações da AHA.

Entretanto, este estudo não avaliou as habilidades práticas dos enfermeiros no atendimento à PCR. Vale lembrar também que a coleta de dados do presente estudo se deu em maio e abril de 2016 e as novas diretrizes da AHA foram publicadas em outubro de 2015, tendo o profissional sete meses para se atualizar. Não se avaliou aqui se o tempo decorrido entre a publicação das diretrizes e a aplicação do questionário apresentaria algum impacto no conhecimento dos participantes, uma vez que os mesmos teriam um maior tempo para se capacitarem.

Outro questionamento que emergiu deste estudo foi como tem se dado o processo de formação do enfermeiro no que se refere ao ensino do atendimento à PCR. A formação deste profissional reflete-se no seu conhecimento e na busca por atualização acerca da temática? Novos estudos precisam ser realizados para responder tais questionamentos.

É de suma importância que os enfermeiros, que são líderes de suas equipes, estejam atualizados e capacitados para executarem o novo protocolo de RCP (2015), pois assim ofertarão um atendimento mais seguro, rápido e eficaz aos pacientes em PCR.

\section{REFERENCES}

1 - Sociedade Brasileira de Cardiologia. I Diretriz de ressuscitação cardiopulmonar e cuidados cardiovasculares de emergência da Sociedade Brasileira de Cardiologia. Arq Bras Cardiol. 2013 [Acesso em 20 nov 2015];101(2 suple.3):1-221. Disponível

em:

http://publicacoes.cardiol.br/consenso/2013/Dir etriz Emergencia.pdf

2 - Rosa MR. Atuação e desenvolvimento do enfermeiro frente ao cliente/paciente vítima de parada cardiorrespiratória (PCR): revisão de literatura. Rev Saúde Foco. 2014 [Acesso em 20 nov 2015];136-148. Disponível em: http://unifia.edu.br/revista eletronica/revistas/s aude foco/artigos/ano2014/atua e desen do e nfermeiro.pdf

3 - Alves CA, Barbosa CNS, Faria HTG. Parada cardiorrespiratória e enfermagem: o conhecimento acerca do suporte básico de vida. Cogitare Enferm. 2013;18(2):296-301. https://doi.org/10.5380/ce.v18i2.32579

4 - Tallo FS, Junior RM, Guimarães HP, Lopes RD, Lopes AC. Atualização em reanimação cardiopulmonar: uma revisão para o clínico. Rev Bras Clin Med. 2012 [Acesso em 26 nov 2015];10(3):194-200. Disponível em: http://files.bvs.br/upload/S/1679-

1010/2012/v10n3/a2891.pdf

5 - American Heart Association. Guidelines for cardiopulmonary resuscitation and emergency cardiovascular care. Part 5: Adult Basic Life Support. Circulation. 2015;132:S414-35. https://doi.org/10.1161/CIR.0000000000000259

6 - American Heart Association. Guidelines for cardiopulmonary resuscitation and emergency cardiovascular care. Part 7: adult advanced cardiovascular life support. Circulation. 2015;132:S444-64.

https://doi.org/10.1161/CIR.0000000000000261

7 - Moura LTR, Lacerda LCA, Gonçalves DDS, Andrade RB, Oliveira YR. Assistência ao paciente em parada cardiorrespiratória em unidade de terapia intensiva. Rev RENE. 2012;13(2):419-27. https://doi.org/10.15253/rev\%20rene.v13i2.3947 8 - Santos LP, Rodrigues NAM, Bezerra ALD, Sousa MNA, Feitosa ANA, Assis EV. Parada cardiorrespiratória: principais desafios vivenciados pela enfermagem no serviço de urgência e emergência. Rev Interdisciplinar Saúde. 2016 [Acesso em 26 nov 2015];3(1):35-53. Disponível em: http://www.interdisciplinaremsaude.com.br/Volu me 9/Trabalho 03.pdf 
9 - Costa KP, Botarelli FR, Fernandes APNL, Carvalho DPSRP, Araújo JNM, Vitor AF. Atuação da equipe de enfermagem no atendimento à parada cardiorrespiratória cerebral. Cult Cuid. 2015;19(42):147-53. Disponível em: https://rua.ua.es/dspace/bitstream/10045/49337 L1/Cultura-Cuidados 42 13.pdf

10 - American Heart Association. Guidelines for cardiopulmonary resuscitation and emergency cardiovascular care. Part 4: Systems of care and continuous quality improvement. Circulation. 2015;132:S397-413.

https://doi.org/10.1161/CIR.0000000000000258 11 - Fernandes FLG, Silva MFP, Pereira TKA, Bezerra ALD, Temoteo RCA, Rosa VCS. Dificuldades encontradas pela enfermagem durante a assistência a vítima de parada cardiorrespiratória. J Med Health Promot. 2016 [Acesso em 19 ago 2016];1(2):189-200. Disponível em: http://jmhp.fiponline.edu.br/publicacoes/v$\underline{1-n-2}$

12 - Moraes CLK, Paula GMA, Silva JR, Rodrigues MCL. Desafios enfrentados pela equipe de enfermagem na reanimação cardiorrespiratória em uma unidade de emergência hospitalar. REES. 2016 [Acesso em 2 set 2016];5(1):90-9.Disponível em:

http://revistaadmmade.estacio.br/index.php/sau desantacatarina/article/viewFile/2231/1056 13 - Cunha CM, Toneto MAS, Pereira EBS. Conhecimento teórico dos enfermeiros de hospital público sobre reanimação cardiopulmonar. Biosci J. 2013 [Acesso em 2 set 2016];29(5):1395-402. Disponível em: http://www.seer.ufu.br/index.php/biosciencejour nal/article/view/17175

14 - Veiga VC, Carvalho JC, Amaya LEC, Gentile JKA, Rojas SSO. Atuação do time de resposta rápida no processo educativo deatendimento da parada cardiorrespiratória. Rev Bras Clin Med. 2013 [Acesso em 1 out 2016];11(3):258-62. Disponível em: http://files.bvs.br/upload/S/16791010/2013/v11n3/a3758.pdf

15 - Ferreira JVB, Ferreira SMB, Casseb GB. Perfil e conhecimento teórico de médicos e enfermeiros em parada cardiorrespiratória, município de Rio Branco, AC. Rev Bras Cardiol. 2012 [Acesso em 1 out 2016];25(6);464-70. Disponível

http://www.rbconline.org.br/artigo/perfil-econhecimento-teorico-de-medicos-eenfermeiros-em-parada-cardiorrespiratoriamunicipio-de-rio-branco-ac/
16 - Oliveira ADS, Cardoso FJB, Sá JF, Araújo OF, Cordeiro ATCB, Vieira TS. Atendimento do enfermeiro do serviço de urgência à vítima em parada cardiorrespiratória. Rev Interdisciplin. 2013 [Acesso em 1 out 2016];6(2):64-74. Disponivel em: http://revistainterdisciplinar.uninovafapi.edu.br/i ndex.php/revinter/article/view/50

17 - Barreto BMF, Tavares DN, Brandão JL, Gonçalves JCP, Valente GSC, Ferreira FC. Continuing/permanent education as a strategy for managing of nursing in the unique health system: an integrative review. Res Fundam Care. 2013;5(3):85-93. http://dx.doi.org/10.9789/21755361.2013.v5i3.85-93

18 - Dane FC, Russell-Lindgren KS, Parish DC, Durham MD. In hospital resuscitation: association between ACLS training and survival to discharge. Ressucitation. 2000;47(1):83-7.

19 - MA, Cesar LA, Nusbacher A, Kern KB, Timerman S, Ramires JA. Advanced cardiac life support training improveslong-term survival from in-hospital cardiac arrest. Resuscitation. 2007;72(3):458-65.

Nota: Artigo original proveniente de Trabalho de Conclusão de Curso. Viçosa, Minas Gerais: Departamento de Medicina e Enfermagem, Universidade Federal de Viçosa; 2016.

Recebido em: 23/02/2017

Aprovado em: 06/11/2017

Endereço de correspondência:

Flávia Batista Barbosa de Sá Diaz

Rua Nasser Simão Muanis, no 355

CEP: 36570-000 Viçosa/MG - Brasil

E-mail: flaviabatista@ufv.br 